\title{
Publicações em psicologia do desenvolvimento em dois periódicos nacionais na década de 1990
}

\author{
Luciana Karine de Souza \\ Gustavo Gauer ${ }^{1}$ \\ Cláudio S. Hutr.
}

\begin{abstract}
Resumo
No intuito de investigar o crescimento da psicologia do desenvolvimento como campo de pesquisa no Brasil, este estudo examinou 40 artigos da área, publicados em dois periódicos nacionais, entre 1991 e 2000. Os artigos foram analisados quanto a autoria, aspectos metodológicos e uso de referências. Os resultados indicaram a prevalência de artigos empíricos, de estudos com crianças e adolescentes, e do uso de técnicas de análise descritivas. Verificou-se ainda uma concentração da produção no Estado de São Paulo e em universidades públicas. Uma análise comparando as duas metades da década mostrou um aumento significativo na proporção de referências recentes e de referências a artigos e capítulos de livros. Os resultados são discutidos no contexto brasileiro de crescimento da pesquisa em psicologia e da consolidação da área de psicologia do desenvolvimento.

Palavras-Chave: Psicologia do Desenvolvimento; Cientometria; Publicações científicas; Artigos; Periódicos.
\end{abstract}

\section{Publications in developmental psychology in two Brazilian journals in the 1990s}

\begin{abstract}
The present paper aimed to assess the growth of developmental psychology as a research field in Brazil. Forty papers, published by two leading Brazilian psychology journals between 1991 and 2000, were analyzed. This analysis consisted of an examination of authorship, methodological aspects, and the use of references. The results indicated the prevalence of empirical papers, studies with children and adolescents, and the use of descriptive statistical techniques. Most of the research was conducted in the state of São Paulo and by researchers from federal and state universities. A comparison of the first and second halves of the decade showed a significant increase in the proportion of recent references as well as references to books and chapters. The results are discussed within the Brazilian context of the advances in research in the field of developmental psychology.

Keywords: Developmental psychology; Scientometrics; Scientific publications; Journal articles.
\end{abstract}

A psicologia do desenvolvimento é uma área consolidada no campo da pesquisa psicológica no Brasil. Entretanto, sua inserção é recente se comparada a áreas mais tradicionais, como psicologia da personalidade. Essa observação é atestada pelo histórico da implantação de programas de pós-graduação (PPGs) nesta área no Brasil. Afora o PPG em Psicologia Escolar e do Desenvolvimento Humano da Universidade de São Paulo, criado em 1970, vários programas iniciaram atividades durante as décadas de 1980 e 1990. Esses programas contribuíram substancialmente para o amadurecimento que a psicologia do desenvolvimento tem experimentado enquanto área de pesquisa.

A pesquisa em psicologia, de modo geral, conheceu grandes avanços no Brasil ao longo dos anos 1990. Especificamente em psicologia do desenvolvimento humano, há poucos estudos publicados (Biaggio,
1989, 1992; Biaggio \& Monteiro, 1998; Matos, 1992; Piccinini \& Lopes, 1993). Em geral, os autores apontaram uma tendência de consolidação da área. Todavia, com exceção de Biaggio e Monteiro (1998), estes estudos examinaram a produção científica em desenvolvimento humano pela análise de publicações nos anos 1980. Com relação à década de 1990, não foram encontradas análises similares dedicadas à psicologia do desenvolvimento.

$\mathrm{O}$ crescimento da produção em uma ciência ou campo de estudo também pode ser avaliado pelo levantamento dos trabalhos publicados por seus pesquisadores. $\mathrm{O}$ presente estudo investigou características da produção científica brasileira em psicologia do desenvolvimento na década de 1990 , através da avaliação de artigos publicados em dois periódicos nacionais. Tendo em vista acompanhar o desdobramento histórico da

\section{${ }^{1}$ Endereço para correspondência:}

Universidade Federal do Rio Grande do Sul, Instituto de Psicologia

Rua Ramiro Barcelos, 2.600, s. 101 - Porto Alegre-RS - 90035-003 - Tel.: (51) 3316-5246, Fax (51)3316-5473

E-mail: gustavogauer@hotmail.com

Os autores agradecem à bibliotecária do Instituto de Psicologia da UFRGS, Viviane Carrion Castanho. Este trabalho contou com o apoio financeiro de CNPq e CAPES. 
área, as perguntas que orientaram este estudo foram formuladas com base em trabalhos anteriores. Assim, antes de considerar os dados da década de 1990, compete apresentar uma revisão de estudos sobre a produção científica em psicologia do desenvolvimento no Brasil na década de 1980.

Biaggio (1989) identificou diversos grupos brasileiros que realizavam pesquisas em psicologia do desenvolvimento, citando uma numerosa série de trabalhos publicados, principalmente nos anos 1980. A autora apontou as teorias piagetiana, freudiana e comportamentalista como principais abordagens do desenvolvimento adotadas no país. Outrossim, teorias mais recentes, que vinham se estabelecendo internacionalmente, já encontravam adeptos no Brasil, como a abordagem ecológica de Urie Bronfenbrenner e o processamento de informação. Nesse mesmo texto, Biaggio definiu a psicologia do desenvolvimento como o estudo das mudanças comportamentais, desde o período pré-natal até a morte. Posteriormente, Biaggio (1992) admitiu a dificuldade em se determinar com clareza os limites desta área em virtude de suas intersecções com outras áreas da psicologia, como a da personalidade, bem como com outras ciências (por exemplo, a sociologia). A autora concluiu que o verdadeiro diferencial da psicologia do desenvolvimento para as demais áreas de pesquisa é uma constante preocupação com as mudanças ao longo do desenvolvimento.

Matos (1992) examinou os projetos de pesquisa nos relatórios da Comissão de Aperfeiçoamento do Pessoal de Ensino Superior (CAPES) dos PPGs brasileiros em psicologia, entre 1980 e 1987. Os projetos de cada área da psicologia foram avaliados em razão de seus temas principais, populações estudadas, delineamentos de pesquisa e instrumentos mais utilizados. Com relação à psicologia do desenvolvimento, concluiu-se que predominavam estudos do comportamento da criança, sem menção a populações adultas e idosas. A ênfase em processos sociais do desenvolvimento vinha dando lugar ao foco no desenvolvimento de processos cognitivos. Em geral, não havia projetos longitudinais, prevalecendo estudos diferenciais e descrições de grupos etários. No conjunto dos PPGs, cumpre assinalar que, no período examinado, 14 dos 17 cursos apresentaram projetos relacionados ao desenvolvimento humano. Quanto à metodologia, esses projetos eram predominantemente levantamentos preliminares e descritivos de fenômenos e circunstâncias do desenvolvimento (63\%), com menores proporções de estudos experimentais, de aplicação e intervenção. As técnicas mais utilizadas foram observações $(40 \%)$, e inventários, escalas e testes (28\%), com pouca presença de entrevistas, questionários e equipamentos de laboratório. A autora constatou que, embora houvesse muitos projetos de pesquisa em psicologia do desenvolvimento, eles resultavam em poucas publicações na área, quando comparados à taxa de publicações nas outras áreas da psicologia.

Piccinini e Lopes (1993) avaliaram artigos de periódicos científicos e resumos de comunicações de pesquisa de congressos nacionais na área de psicologia infantil na segunda metade da década de 1980. Foram examinados trabalhos relativos a populações do período pré-natal até os 12 anos de idade. Do total de 1.615 comunicações em congressos, $35 \%$ enquadraram-se na área de psicologia infantil. Entre os artigos, essa porcentagem foi de $27 \%$. Quanto à produção em psicologia infantil, os autores identificaram uma dispersão na escolha de temas, uso de delineamentos simples e prevalência de estudos em educação especial e de adaptação, construção ou validação de testes. Processos cognitivos foram mais abordados em artigos, enquanto a interação criança-criança foi o tema mais freqüente nos resumos de comunicações. As técnicas de coleta de dados mais utilizadas nos artigos foram escalas e entrevistas e, nas comunicações, observação. As análises de dados, consideradas muito simples pelos autores, consistiam predominantemente em estatísticas descritivas nos artigos, e muitas vezes não chegavam a ser explicitadas nos resumos de comunicações. Entre os artigos, $24 \%$ utilizaram técnicas qualitativas de análise dos dados.

Os estudos revisados apresentam resultados referentes à produção brasileira em psicologia do desenvolvimento nos anos 1980. De modo geral, podese dizer que foram verificados: 1) uma relativa variedade de temas, passível de ser atribuída à dificuldade em delimitar o campo (Biaggio, 1992); 2) ênfase no desenvolvimento infantil em detrimento de outras faixas etárias; 3 ) uso preferencial de observação e de instrumentos psicométricos, com tratamento estatístico simples (descritivo); e 4) ascensão de abordagens teóricas cognitivas e decréscimo de enfoques comportamentalistas. Lembramos que, ao final da década de 1980, foram fundados PPGs com área de concentração em psicologia do desenvolvimento. Conseqüentemente, mudanças nesse panorama seriam esperadas.

Biaggio e Monteiro (1998) revisaram a situação da pesquisa brasileira em psicologia do desenvolvimento na década de 1990. As autoras observaram o ressurgimento internacional de interesses abandonados na segunda metade do século XX, como o desenvolvimento emocional, representado pelos estudos do apego mãepai-bebê, e a pesquisa das bases biológicas e genéticas do desenvolvimento. No Brasil, as tendências identificadas anteriormente por Biaggio (1989) aprofundaram-se, ao mesmo tempo em que surgiram novas direções na pesquisa e intervenção em desenvolvimento humano. Em destaque está a orientação para a relevância do contexto cultural e a abordagem de problemas sociais 
prementes como o das crianças em situação de rua (temática prevista por Biaggio, 1992).

Naturalmente, a maior parte da produção científica em psicologia no país vem da pós-graduação, que evoluiu na década de 1990, tanto em psicologia do desenvolvimento, como nas demais áreas. Uma evidência do crescimento desta área foi a criação da Sociedade Brasileira de Psicologia do Desenvolvimento (SBPD) em 1998, ocorrida no II Congresso Brasileiro de Psicologia do Desenvolvimento em Gramado, RS. Segundo Roazzi (2003), a fertilidade da psicologia do desenvolvimento no Brasil é atestada pelo crescimento substantivo no número de trabalhos inscritos nos congressos da SBPD.

Embora apontem para mudanças, os dados referentes aos anos 1980 não estão amparados em indicadores consensuais de produção científica. O objetivo deste estudo é contemplar uma parte representativa da produção brasileira em psicologia do desenvolvimento nos anos 1990, com base em um conjunto de critérios operacionais de avaliação. São formuladas as seguintes perguntas acerca da trajetória brasileira da psicologia do desenvolvimento na década de 1990: Houve mudanças nas faixas etárias estudadas, com a inclusão de adultez e envelhecimento? Esses estudos utilizaram análises estatísticas mais sofisticadas do que as usadas nos anos 1980? Aumentou o número de estudos qualitativos? Houve mais parcerias interinstitucionais e internacionais? Alteraram-se os padrões de uso de referências?

\section{Método}

Este estudo analisou artigos brasileiros da área da psicologia do desenvolvimento em dois periódicos nacionais classificados como Nacional A pela CAPES, em 2002: Psicologia: Reflexão e Crítica, da Universidade Federal do Rio Grande do Sul (Porto Alegre, RS), editada desde 1986, com periodicidade quadrimestral e Psicologia: Teoria e Pesquisa, da Universidade de Brasília, publicada desde 1985, também quadrimestral. De cada revista, foram selecionados 20 artigos, publicados na década de 1990 (de 1991 a 2000). Por artigo entende-se um trabalho original que apresente resultados de pesquisas ou formulações teóricas na área de pesquisa a que se refere. Neste estudo, selecionaram-se artigos em psicologia do desenvolvimento humano, com o primeiro autor proveniente de instituição brasileira. Excluíram-se resenhas, relatos de atividades e experiências, entrevistas, notícias e editoriais. Como as duas revistas consultadas são generalistas, foi necessário selecionar os artigos referentes à área de interesse. A seleção levou em conta o título, o resumo ou as palavras-chave do artigo. Com base em Biaggio (1989; 1992) e Matos (1992), o critério para inclusão na categoria psicologia do desenvolvimento considerou estudos que tratem de mudanças em comportamentos e/ou sistemas de respostas motoras, perceptuais, cognitivas, lingüísticas e sociais, ocorridas do período pré-natal à morte. Em cada número dos volumes editados entre 1991 e 2000, foram selecionados os primeiros dois artigos que se enquadravam no critério acima. Quando o artigo não correspondia ao critério estipulado, passava-se ao próximo artigo, e assim por diante, até que se obtivessem artigos de todos os números.

Da revista Psicologia: Teoria e Pesquisa obtivemos 2 artigos de cada volume, ou seja, 2 textos por ano, de 1991 a 2000. Da revista Psicologia: Reflexão e Crítica, os volumes de 1992, 1994, 1995, 1996 e 1999 foram representados por 2 artigos cada; os volumes de 1997, 1998 e 2000 por 3 artigos de cada ano; e no ano de 1993 encontrou-se apenas 1 artigo que se enquadrou na área de psicologia do desenvolvimento. Ressalte-se que Psicologia: Reflexão e Crítica não foi publicada em 1990 e 1991.

Cada artigo foi avaliado em relação a três grupos de itens: características da autoria dos artigos, características dos artigos empíricos, e uso de referências. As variáveis são descritas a seguir.

Quanto à autoria, contou-se o número de autores e, nos casos de artigos com mais de um autor, classificou-se o tipo de parceria, se local (autores da mesma instituição), nacional (de instituições brasileiras diferentes, inclusive dentro de um mesmo estado) ou internacional. A procedência institucional do primeiro autor foi categorizada em instituição de ensino superior federal, estadual, particular ou outras instituições. Quando houver referência ao autor do artigo, entendase, no caso de textos com mais de um autor, que se trata apenas do primeiro. Foi computada também a procedência geográfica do autor (cidade e estado).

Inicialmente, os artigos foram classificados como empíricos (com coleta e análise de dados) ou teóricos. Os artigos empíricos foram analisados quanto ao sexo dos participantes, conforme as categorias masculino, feminino, comparação ou indistinto (neste último caso, são citados ambos os sexos, sem comparação). Para faixa etária, foram utilizadas as categorias pré-natal, bebê (0-3 anos), criança (4-11 anos), adolescente (12-17 anos), adulto-jovem (18-25 anos), adulto (26-59 anos), e idoso (acima de 60 anos). Observou-se o tamanho da amostra e classificaram-se as técnicas de análise dos dados em descritivas, inferenciais simples e complexas, modelagem e qualitativas (fenomenologia, análise de conteúdo, etc.). No caso de mais de um tipo de técnica quantitativa, considerou-se a mais complexa.

As referências citadas nos artigos foram classificadas por idioma, tipo e idade. Quanto ao idioma, distinguiram-se referências em língua portuguesa (inclusive textos de autores estrangeiros traduzidos para o português) 
daquelas em língua estrangeira. Cada referência foi categorizada como artigo de periódico científico, livro, capítulo de livro, dissertação ou tese, resumo publicado, divulgação eletrônica, e outros tipos de referências (relatórios, documentos, etc.), e classificadas como nova (até 5 anos antes do ano de publicação do artigo), jovem (de 6 a 15 anos antes), e antiga (mais de 15 anos). Foram contadas, ainda, as auto-referências do primeiro autor do artigo.

A aferição dos itens foi realizada pelos dois primeiros autores que, em caso de discordância, consultavam o terceiro autor para desempate. Calcularamse freqüências, porcentagens e médias de todos os itens. A comparação entre as duas metades da década para autoria, características de artigos empíricos e uso de referências foi realizada por meio de Teste de Diferenças de Proporções, disponível no pacote Statistica 6.

\section{Resultados}

\section{Autoria dos artigos}

Quanto ao número de autores por artigo, 13 $(32,5 \%)$ dos 40 artigos foram publicados por 1 único autor; 16 artigos (40\%) foram escritos por 2 autores; 5 textos $(12,5 \%)$ apresentaram 3 autores; e 6 trabalhos $(15 \%)$ tinham entre 4 e 6 autores. Grande parte dos artigos, portanto, foi escrita por 1 ou 2 autores. Entre os anos de 1991 e 1995, o número de autores variou entre 1 e 6, enquanto na segunda metade da década a variação diminuiu para uma faixa de 1 até 4 autores, em geral, por artigo. Por outro lado, a produção individual aumentou de $29,4 \%$ na primeira metade da década, para $34,8 \%$ na segunda metade, embora a diferença não seja estatisticamente significativa. A autoria em duplas de autores também apresentou aumento de uma para outra metade da década: no primeiro período, registraram-se $17,6 \%$ de artigos escritos por dois autores, enquanto no segundo, essa porcentagem foi de 56,5\%, sendo a diferença entre as proporções significativa $(p<0,02)$.

Dentre os 27 artigos com mais de um autor, 20 deles $(74,1 \%)$ formaram parceria local, 5 deles $(18,5 \%)$ organizaram parceria nacional, e em apenas 2 artigos $(7,4 \%)$ houve parceria internacional. Prevaleceram, de modo geral, parcerias locais na autoria das publicações dedicadas à psicologia do desenvolvimento na década de 1990. Dividindo-se a década em duas metades, observou-se que as parcerias nacionais aumentaram significativamente ao longo da década, de $5,9 \%$ para $17,4 \%(\mathrm{p}<0,01)$. As demais modalidades de parcerias (local e internacional) não se alteraram.

Com relação à procedência geográfica, 10 autores provêm de instituições do Rio Grande do Sul (9 de Porto Alegre); 9 de São Paulo (4 da capital); 8 de instituições pernambucanas ( 7 de Recife); 5 do Distrito Federal; 4 do Rio de Janeiro (3 da capital); e 1 caso em cada uma das seguintes capitais: João Pessoa (Paraíba), Maceió (Alagoas), Salvador (Bahia) e Vitória (Espírito Santo). A região sudeste é então representada por 3 estados e um total de 14 autores, seguida da região nordeste (11 autores) e sul (10 autores), embora nesta última constem autores de um único estado. Note-se também que a maioria dos autores provém de capitais (31 casos). Na transição entre os períodos 1991-1995 e 1996-2000, houve um aumento de 8 para 15 cidades diferentes; especificamente quanto às cidades do interior, passou-se de 1 para 8 localidades.

No tocante ao tipo de instituição, 28 artigos ( $70 \%$ do total de 40$)$ foram encaminhados por 10 universidades federais diferentes; $11(27,5 \%)$ por 6 diferentes instituições de ensino estaduais; e apenas 1 texto por universidade particular. Portanto, quase todos os artigos relacionados à área da psicologia do desenvolvimento foram produzidos em universidades públicas. De 1991-1995 para 1996-2000, a porcentagem de federais diminuiu de $76,5 \%$ para $65,2 \%$, enquanto a de estaduais apresentou um ligeiro aumento de 23,5\% para 30,4\%. Contudo, nenhuma dessas alterações foi estatisticamente significativa.

\section{Artigos empiricos}

Em 40 artigos analisados de toda a década, 11 são textos teóricos $(27,5 \%)$ e 29 são trabalhos empíricos $(72,5 \%)$. Considerando-se a década por metades, praticamente não há alteração, apenas com o primeiro período levemente superior em textos teóricos - 29,4\% de teóricos e 70,6\% de empíricos no período de 19911995; e de 1996 a 2000 obtiveram-se 26,1\% de teóricos e 73,9\% de empíricos.

Nos 29 artigos empíricos identificados, a faixa etária mais estudada foi a de crianças, com um total de 13 artigos $(44,8 \%)$. Dez outros trabalhos $(34,5 \%)$ contaram com grupos de participantes de mais de uma faixa etária (na maioria, crianças e adolescentes); 4 artigos (13,8\%) investigaram adolescentes; 1 artigo analisou bebês; 1 artigo estudou adultos; e em nenhum artigo empírico participaram idosos. Os trabalhos com crianças aumentaram da primeira metade da década para a segunda (de 29,4\% para $34,8 \%)$.

Apenas 4 dos artigos empíricos (13,8\%) compararam participantes do sexo feminino e masculino, e os demais 24 trabalhos $(82,8 \%)$ não fizeram esse tipo de comparação, 1 artigo não informou o sexo dos participantes (tratava-se apenas de crianças), e nenhum trabalho investigou exclusivamente um dos sexos. Entretanto, passou-se de nenhuma comparação no período de 1991-1995 para 17,4\% do tipo em 1996-2000.

No tamanho de amostra, 7 artigos $(24,1 \%)$ abrangeram até 15 participantes; 12 trabalhos (41,4\%) envolveram entre 16 e 60 pessoas; $6(20,7 \%)$ artigos 
estudaram de 61 a 150 participantes; 3 trabalhos $(10,3 \%)$ trataram de 151 a 300 pessoas; e 1 trabalho contou com mais de 300 participantes. Assim, aproximadamente dois terços dos artigos empíricos utilizaram amostras com até 60 pessoas.

Com relação à análise dos dados, 5 artigos $(17,2 \%)$ utilizaram procedimentos qualitativos de análise. Nos demais 24 artigos empíricos (82,8\%), empregou-se mais de uma técnica estatística, resultando em 17 ocorrências de técnicas inferenciais $(70,8 \%$ do total de 24$)$ e 7 descritivas (29,2\%). Enquanto estas últimas aumentaram de $11,8 \%$ para $21,7 \%$ de uma metade da década para outra, as técnicas qualitativas de análise dos dados diminuíram de $17,6 \%$ para 8,7\%. Na comparação entre as duas metades da década, os Testes de Diferenças de Proporções para os itens de características dos artigos empíricos (tipo de artigo, faixa etária, sexo, tamanho de amostra, técnica de análise) não revelaram diferenças estatisticamente significativas para as alterações observadas entre as duas metades da década de 1990.

\section{Uso de referências}

Os 40 artigos somaram o uso de 1.192 referências, com uma média de 29,8 referências por artigo na década inteira. Os 17 artigos da primeira metade da década somaram 379 referências (média de 22,3 referências por artigo). Os 23 artigos da segunda metade totalizaram 813 referências (média de 35,3 por artigo). Inicialmente, cabe comentar alguns dados interessantes relativos a toda a década estudada. Dentre eles, está a total ausência de referências eletrônicas, bem como, em todos os 40 artigos examinados, a presença mínima de 1 referência antiga, 1 referência jovem, 1 referência em idioma estrangeiro e 1 referência à consulta a um livro. Além disso, observou-se que o total de referências citadas nos artigos variou de 7 consultas até a citação de 104 fontes bibliográficas; o primeiro caso foi um artigo empírico com 3 autores, enquanto o segundo texto foi teórico e escrito por 2 autores.

Quanto à idade das referências, observou-se um aumento significativo de referências novas, de 16,6\% na primeira metade da década para $24,8 \%$ na segunda $(\mathrm{p}<$ $0,01)$, e uma redução no uso de referências antigas, de $41,9 \%$ para $29,5 \%$ ( $p<0,01)$. O uso de referências jovens, por outro lado, aumentou de forma não significativa, de $41,4 \%$ no primeiro período para $45,6 \%$ no segundo. Foi significativo o aumento observado no uso de referências em línguas estrangeiras, passando de $70,4 \%$ para $76,6 \%(\mathrm{p}<0,03)$.

Com respeito ao tipo de referência, houve crescimento significativo no uso de artigos, de 44\% na primeira metade da década para $51,9 \%$ na segunda $(\mathrm{p}<$ 0,02 ), bem como de capítulos de livros (de 11\% para $18 \% ; \mathrm{p}<0,01)$. Diminuiu significativamente o uso de livros, de 31,6\% para 20\% ( $\mathrm{p}<0,01)$, e o uso de resumos de congressos (de 5,5\% para $2,2 \% ; \mathrm{p}<0,01)$. O uso de outros tipos de referências (relatórios, legislações, monografias, etc.) e as referências a dissertações e teses praticamente não apresentaram alterações de um período para outro. Nenhuma referência eletrônica foi citada nos 40 artigos examinados.

Do total de 1.192 referências, 79 eram autoreferências. $\mathrm{Na}$ primeira metade da década, a porcentagem de auto-referências foi de 10,5\%, diminuindo para $4,8 \%$ na segunda metade. A diferença aferida foi significativa $(\mathrm{p}<0,01)$.

\section{Discussão}

Os resultados deste estudo devem ser considerados como um indicador parcial, embora substantivo, das tendências da pesquisa em psicologia do desenvolvimento no Brasil na década de 1990. Sabese que muitos trabalhos meritórios são publicados em várias revistas, livros e outros meios. Contudo, o objetivo aqui não foi o de fazer um senso de toda a produção nacional. Considera-se que os artigos aqui examinados consistem numa amostra representativa de produção qualificada da área por terem sido publicados em dois periódicos reconhecidos pela comunidade científica e avaliados com conceito "Nacional A" desde a implementação do sistema de avaliação dos periódicos da ANPEPP/CAPES. Ressalte-se ainda que, na mais recente avaliação, ambas as revistas foram guindadas à categoria "Internacional", o que evidencia a visibilidade, a qualidade e a representatividade da produção publicada nesses dois periódicos. Artigos ali publicados têm alta visibilidade por circularem nacional e internacionalmente e passaram por rigoroso processo editorial. Uma avaliação de impacto dessas publicações, mediante a computação de citações aos artigos, seria bem-vinda como um dos próximos passos no acompanhamento da produção científica nacional em Psicologia do Desenvolvimento.

\section{Autoria: Concentração geográfica versus parcerias nacionais}

Yamamoto, Souza e Yamamoto (1999) ressaltaram a pujança da produção científica nas instituições públicas, que se verifica apesar do sucateamento dessas universidades. De fato, quase toda a produção em psicologia do desenvolvimento publicada no Brasil, representada pelos artigos aqui examinados, proveio de 16 diferentes instituições públicas de ensino superior. Esse dado é corroborado pela distribuição dos programas brasileiros de pós-graduação, situados em sua maioria em instituições públicas. Praticamente todos os programas na área da psicologia do desenvolvimento no Brasil encontram-se nesse tipo de instituição.

A escassez de cooperações interinstitucionais 
observada por Hutz e Adair (1996) foi confirmada pelos resultados deste estudo referente à primeira metade da década de 1990. Todavia, na comparação entre as duas metades da década, esse quadro modificou-se significativamente no que tange a cooperações entre pesquisadores de instituições diferentes dentro do Brasil. Apesar disso, a maioria das parcerias encontradas ainda é local. Embora as parcerias internacionais permaneçam pouco freqüentes, é de se esperar que a próxima década traga um crescimento na cooperação internacional na pesquisa em psicologia do desenvolvimento, em virtude da pressão pelo aumento da produção publicada no exterior. Enquanto a década de 1990 parece ter-se caracterizado pela criação e consolidação de parcerias nacionais, espera-se que nos próximos anos afirme-se um maior grau de colaborações internacionais.

Segundo Biaggio (1992), a maior parte da pesquisa em psicologia do desenvolvimento no Brasil ocorre em São Paulo e Rio de Janeiro, mas com boa representação nas cidades de Recife e João Pessoa e no estado do Rio Grande do Sul. Com relação à procedência geográfica do primeiro autor nos 40 artigos em psicologia do desenvolvimento publicados na década de 1990, a cidade de São Paulo continua em destaque, mas agora lado a lado com Porto Alegre e Recife. Aparentemente, a representação mencionada por Biaggio ao examinar a década de 1980 ainda se mantém, conforme os dados do presente estudo. Por outro lado, podemos destacar a crescente participação da região nordeste, mesmo que os recursos destinados à pesquisa ainda estejam centralizados no sudeste do Brasil. Conquanto os resultados apontem um certo grau de concentração da produção em poucas localidades, devemos ressaltar que eles dizem respeito somente ao primeiro autor de cada artigo. Considerando o resultado referente ao aumento de parcerias dentro do país, esse indicador não implica, necessariamente, uma concentração exacerbada.

\section{Artigos empiricos: tendências em pesquisa}

Hutz e Adair (1996) indicaram uma tendência da psicologia brasileira como um todo em direcionar-se à pesquisa. Nos artigos de psicologia do desenvolvimento aqui investigados, encontrou-se uma maioria de artigos empíricos, o que pode estar refletindo a referida tendência. A criação de PPGs em psicologia do desenvolvimento no final da década de 1980 pode ter contribuído para tal situação, bem como o início de programas em outras áreas que surgiram ao longo dos anos 1990. As pesquisas realizadas no contexto dos PPGs geralmente incluem coleta de dados que levam à produção de dissertações e teses.

Apesar do aumento no número de teses $\mathrm{e}$ dissertações, as referências a esse tipo de trabalho não aumentaram significativamente no período investigado.
Isso provavelmente ocorre pela dificuldade de recuperação deste tipo de produção. $\mathrm{O}$ uso de uma referência é dependente de sua disponibilidade; não se poderia citar um trabalho a que não se tem acesso ou cuja existência é ignorada. De um lado, os artigos estão em grande medida disponíveis eletronicamente, muitas vezes com texto completo, acessível a um grande número de instituições através de portais especializados. De outro lado, os bancos de teses e dissertações ainda se encontram em fases iniciais de implantação, ou são pouco conhecidos. Espera-se que nos próximos anos aumente o montante de citações a esse tipo de produção, assim como ocorreu com os artigos na década passada. No entanto, autores de teses e dissertações têm sido incentivados a publicar os resultados das suas pesquisas na forma de artigos, e muitos dos artigos citados descendem dessa produção, compartilhando os dados coletados.

Matos (1992) apontou que 14 dos 17 cursos de pós-graduação que enviaram relatório para a CAPES entre 1980 e 1987 apresentaram projetos na área do desenvolvimento humano. Contudo, salientou que a produção científica em psicologia do desenvolvimento não se refletia em publicações quando comparada às demais áreas. Considerando-se que a análise da autora conferiu a década de 1980, e que a pesquisa psicológica como um todo avançou em muitos aspectos de uma década para outra, conforme Biaggio e Monteiro (1998), os projetos analisados por Matos provavelmente tornaram-se artigos científicos publicados na década de 1990, identificados no presente estudo nos trabalhos empíricos encontrados.

Com respeito à faixa etária estudada nos artigos empíricos, notou-se que a psicologia do desenvolvimento da década de 1990 ainda dedicava-se substancialmente a crianças e adolescentes, na mesma direção dos relatórios examinados por Matos (1992). A concepção mais recente e ampliada, que considera o desenvolvimento humano do período pré-natal à morte, embora reconhecida nacional e internacionalmente (Roazzi, 2003), ainda não se reflete nos artigos avaliados. Os dados aferidos permitem concluir que esses artigos assumem uma concepção de desenvolvimento cujas principais mudanças se encerram ao final da adolescência, o que pode estar refletindo concepções teóricas que influenciam o entendimento de pesquisadores e profissionais acerca do escopo do desenvolvimento humano.

Biaggio (1992) acreditava que a psicologia do desenvolvimento no Brasil deve preocupar-se em especial com as crianças, em virtude do nível de pobreza em que milhares delas vivem em todo o país e também porque a nossa é uma nação com larga porcentagem de população jovem. Contudo, as estatísticas apontam que já há uma mudança no perfil 
etário da população brasileira, indicando um aumento de idosos e um declínio nos nascimentos. Ademais, do ponto de vista conceitual, é lícito ponderar que o desenvolvimento psicológico continua acontecendo em todo o ciclo vital, ou seja, após a adolescência. Assim, entende-se que a psicologia do desenvolvimento brasileira cresceria ao acompanhar esta mudança, com um conseqüente reflexo em pesquisas e publicações.

A popularização de métodos de análise qualitativos que Hutz e Adair (1996) previram não se refletiu nos artigos em psicologia do desenvolvimento aqui analisados na década de 1990. Apenas 5 de 29 trabalhos empíricos utilizaram técnicas qualitativas de análise dos dados. O trabalho de Piccinini e Lopes (1993), no entanto, embora tenha considerado apenas a psicologia infantil, encontrou $24 \%$ de técnicas qualitativas nas publicações de 1985 a 1990, período anterior ao aqui examinado. É possível que as pesquisas em desenvolvimento que empregam técnicas qualitativas de análise tenham se disseminado, mas o fato é que não vêm sendo publicadas nas revistas aqui contempladas. Considerando que estas revistas estão entre as mais importantes e concorridas no país, é possível que os trabalhos qualitativos submetidos não se enquadrem nas normas de publicação, tampouco nos critérios dos consultores das revistas. A confirmação desta hipótese seria possível mediante uma futura análise da totalidade dos manuscritos submetidos às revistas, comparados aos trabalhos que efetivamente chegam a ser publicados.

\section{Uso de referências: a disponibilidade orienta as práticas}

As características do uso de referências são um importante indicador da maturidade da produção científica em uma área do conhecimento. Da primeira para a segunda metade da década (de 1991-1995 para 1996-2000), o uso de referências proporcionalmente mais novas e mais jovens, o aumento das referências estrangeiras e das referências a artigos sugere uma crescente disponibilidade de periódicos, principalmente estrangeiros. Essa disponibilidade deve-se possivelmente à disseminação de bases de dados eletrônicas. Isso remonta à ausência de referências eletrônicas, até certo ponto justificada na primeira metade da década, mas nem tanto no que tange o período de 1996-2000, quando seu uso já é comum. Realmente, os autores estão utilizando tais veículos em larga escala, o que é um grande avanço em todos os sentidos.

Observou-se que a utilização de livros diminuiu da primeira para a segunda metade da década, sugerindo que eles estejam menos disponíveis, ou menos interessantes, que os artigos. Por outro lado, nota-se que aumentou o uso de capítulos de livros, comparando-se os anos de 1991-1995 e 1996-2000. No mundo inteiro, os intercâmbios internacionais e interinstitucionais têm gerado parcerias para a organização de coletâneas de textos, organizadas por temas, por métodos, ou por populações em comum. Cumpre assinalar que, em se tratando de livros produzidos no Brasil, esse intercâmbio é fomentado pela ANPEPP.

$\mathrm{O}$ acesso a teses e dissertações parece não ter se modificado significativamente ao longo da década, permanecendo escasso. Os trabalhos de pós-graduação não contam com a mesma disponibilidade dos artigos de periódicos: o acesso a eles ainda depende de visitas às bibliotecas e, no caso de grandes distâncias, da colaboração de colegas de pesquisa ou do próprio autor. Espera-se, contudo, que esta situação se altere, em virtude de iniciativas de divulgação na forma de bancos de teses e dissertações mantidos por universidades e, eventualmente, por entidades científicas. Esse advento interessa ao autor, que tem seu trabalho divulgado; ao leitor, que tem acesso à atualidade da produção da pósgraduação; e aos PPGs, que ganham visibilidade. Um outro resultado, que talvez seja o mais importante, é a manutenção de um senso de comunidade científica naquele respectivo campo de pesquisa.

\section{O papel da ANPEPP}

A atuação da ANPEPP tem influenciado a organização e crescimento da pós-graduação em psicologia no país, bem como o incremento do intercâmbio científico. Esses fatores, por sua vez, determinaram em muito os avanços da produção na área. As mudanças nos padrões da produção publicada em psicologia do desenvolvimento, conforme identificadas nos resultados deste estudo, podem ter resultado de políticas científicas definidas pela ANPEPP. Surgida em 1983, por iniciativa de pesquisadores preocupados com a organização e aprimoramento dos programas, essa Associação passou a reunir-se regularmente em Simpósios a partir de 1988 (Seidl de Moura, 2002). Desde o Simpósio de 1989, a ANPEPP organiza Grupos de Trabalho (GTs) dedicados a áreas específicas da pesquisa psicológica. Dos dez grupos iniciais, alguns se consolidaram, sendo fontes importantes de publicações científicas e de efetivas iniciativas de intercâmbio interinstitucional. O crescimento da pesquisa e da pós-graduação em psicologia no Brasil pode ser testemunhado pelo crescimento da ANPEPP: no último Simpósio, realizado em 2002, registrou-se a presença de 32 grupos. Por volta de 1996, a ANPEPP passou a estimular diretamente o intercâmbio entre pesquisadores, mediante a publicação de livros e revistas especiais que representam o trabalho dos GTs.

Ultimamente, a relevância da ANPEPP para a publicação científica foi ampliada em virtude do convite, por parte da CAPES, para deliberar um conjunto de critérios para a avaliação dos periódicos 
científicos em psicologia (Yamamoto e colaboradores, 2002). Os resultados dos processos de avaliação segundo esses critérios são bastante impressionantes, considerandose que a maioria das revistas, em resposta às exigências, tem se aprimorado em quesitos cruciais como qualidade editorial, normalização, regularidade e distribuição. É certo que esses avanços têm feito, e continuarão fazendo, grande diferença na consolidação da produção e divulgação científica em psicologia no Brasil.

\section{Considerações finais}

De início, pode-se discutir o fato de que não foram considerados todos os artigos em psicologia do desenvolvimento que pudessem ser encontrados nas duas revistas em toda a década de 1990. No entanto, a seleção realizada não foi tarefa fácil, tendo em vista o pequeno número de artigos que se enquadraram no critério para psicologia do desenvolvimento. $\mathrm{Na}$ verdade, a indefinição conceitual e a complexidade disciplinar desse campo (Biaggio, 1992) podem ser apontadas como condições que prejudicam a identificação da sua produção. Considera-se, no entanto, que os dados obtidos se fazem representativos. Em certa medida, eles concordam com outros achados da literatura que investigaram a psicologia ou, mais especificamente, a psicologia do desenvolvimento humano.

O presente estudo não replicou diretamente os procedimentos dos estudos citados na introdução, realizados com dados dos anos 1980. Assim, nem sempre foi possível avaliar diferenças objetivas entre as épocas respectivas. A análise que mais propriamente se presta à consideração sobre a evolução da psicologia do desenvolvimento no Brasil é a comparação entre as duas metades da década de 1990. Entre os indicadores levantados, aquele que se destaca é o uso de referências. As mudanças nos padrões de uso de referências parecem relevantes: os trabalhos em psicologia do desenvolvimento têm utilizado maior número de referências e, em geral, têm citado trabalhos mais recentes, o que depõe em favor de reflexos positivos das políticas de publicação que têm sido implementadas.

Nesta oportunidade, partiu-se de duas revistas nacionais em psicologia para a procura de artigos em psicologia do desenvolvimento humano, segundo critérios estipulados (principalmente as definições de artigo e de desenvolvimento). Entende-se que estes resultados podem ser enriquecidos e questionados mediante a realização de novos estudos. Por exemplo, pode-se procurar, em bases de dados nacionais (como Scielo ou Index Psi), artigos publicados na década de 1990 com a palavra-chave desenvolvimento, considerando-se também os demais critérios descritos no método. Estimula-se, ainda, a replicação do presente estudo, utilizando-se critérios cientométricos idênticos ou semelhantes aos aqui descritos. Futuros trabalhos podem avaliar a produção atual de outras áreas da psicologia, bem como comparar os desenvolvimentos históricos de diferentes áreas da psicologia no país, e de diferentes regiões geográficas em um mesmo campo de estudos. Os indicadores assim aferidos podem orientar, de forma objetiva, políticas de apoio à pesquisa e de descentralização da produção científica.

\section{Referências}

Biaggio, A. M. B. (1989). Pesquisa em psicologia do desenvolvimento: tendências e exemplos. Em Associação Nacional de Pesquisa e Pós-Graduação em Psicologia (Org.). Anais do II Simpósio Brasileiro de Pesquisa e Intercâmbio Científico. (pp. 9-34). Rio de Janeiro, RJ: ANPEPP.

Biaggio, A. M. B. (1992). Emerging trends in developmental psychology in Brazil. Revista Interamericana de Psicologia, 26(2), 223-230.

Biaggio, A. M. B. \& Monteiro, J. K. (1998). A psicologia do desenvolvimento no Brasil e no mundo. Em M. L. S. Moura, J. Correa \& A. Spinillo (Orgs.). Pesquisas brasileiras em psicologia do desenvolvimento. (pp. 15-31). Rio de Janeiro, RJ: UERJ.

Hutz, C. S. \& Adair, J. G. (1996). The use of references in Brazilian psychology journals reveals trends in thought and research. International Journal of Psychology, 31(2), 145-149.

Matos, M. A. (1992). A pesquisa em psicologia no Brasil na década de 80: características, instrumentos e distribuição institucional. Em Associação Nacional de Pesquisa e Pós-Graduação em Psicologia (Org.). Cadernos da ANPEPP, 1. (pp. 135-157). São Bernardo do Campo, SP: ANPEPP.

Piccinini, C. A. \& Lopes, R. C. S. (1993). A pesquisa em psicologia infantil no Brasil: Alguns aspectos críticos. Em Associação Nacional de Pesquisa e Pós-Graduação em Psicologia (Org.). Cadernos da ANPEPP, 2. (pp. 4355). São Paulo, SP: ANPEPP.

Roazzi, A. (2003). Contextos de desenvolvimento humano, educação e cultura: Psicologia do Desenvolvimento no Brasil hoje. Em Sociedade Brasileira de Psicologia do Desenvolvimento (Org.). Anais do IV Congresso Brasileiro de Psicologia do Desenvolvimento. (pp. 13-23). João Pessoa, PB: ANPEPP.

Seidl de Moura, M. L. (2002). Treze anos de grupos de trabalho nos simpósios da ANPEPP: algumas tendências e evidências de promoção de maior integração. Em Associação Nacional de Pesquisa e PósGraduação em Psicologia (Org.). Anais do IX Simpósio 
de Pesquisa e Intercâmbio Cientifico da ANPEPP. (pp. 1928). Rio de Janeiro, RJ: ANPEPP.

Yamamoto, O. H., Souza, C. \& Yamamoto, M. E. (1999). A produção científica na psicologia: uma análise dos periódicos brasileiros no período 19901997. Psicologia: Reflexão e Crítica, 12(2), 549-565.

Yamamoto, O. H., Menandro, P. R. M., Koller, S. H., Lobianco, A. C., Hutz, C. S., Bueno, J. L. O. \& Guedes,
M. C. (2002). Avaliação de periódicos científicos brasileiros da área de psicologia. Ciência da Informação, 31(2), 163-177.

Enviado em junho de 2003

Reformulado em maio de 2004

Aprovado em maio de 2004

Sobre os autores:

Luciana Karine de Souza é psicóloga, mestre em Psicologia e doutoranda pelo Programa de Pós-Graduação em Psicologia do Desenvolvimento da Universidade Federal do Rio Grande do Sul.

Gustavo Gauer é psicólogo, mestre em Psicologia e doutorando em Psicologia pelo Programa de Pós-Graduação em Psicologia do Desenvolvimento da Universidade Federal do Rio Grande do Sul.

Cláudio S. Hutz é professor titular do Departamento de Psicologia do Desenvolvimento e da Personalidade do Instituto de Psicologia da Universidade Federal do Rio Grande do Sul, e do Programa de Pós-Graduação em Psicologia do Desenvolvimento. 
O LAPSaM desenvolve estudos sobre avaliação psicológica em contextos de saúde mental, com a validação de instrumentos e suas aplicações. Os estudos têm enfocado instrumentos psicométricos, neuropsicológicos e técnicas projetivas, apoiando-se em métodos quantitativos e qualitativos. Participam do laboratório alunos de pós-graduação e de iniciação científica.

Professores responsáveis:

Alessandra Gotuzo Seabra Capovilla

alessandra.capovilla@saofrancisco.edu.br

Anna Elisa de Villemor Amaral

anna.villemor@saofrancisco.edu.br

Cláudio Garcia Capitão

claudio.capitao@saofrancisco.edu.br

Makilin Nunes Baptista

makilim.baptista@saofrancisco.edu.br 